4) the continuation of the present efforts to identify and monitor particularly threatened species and habitats. This is already done through groups of experts and monitoring procedures such as the opening and maintenance of special files;

5) elaboration of a European strategy for the conservation of Nature/Biodiversity. (This can be done under the terms of Art. 2 and Art. 3, paragraph 1 of the Convention, which ask parties to take measures to maintain the populations of wild species at satisfactory levels and to promote policies for the conservation of wildlife and natural habitats);

6) protection of non-wild species, such as endangered crops, cultivars, rare livestock varieties, etc. Although these aspects are not contemplated now in the Convention, it would only require the will of the parties to develop conservation action in this field, mainly by way of recommendations and development and implementation of programmes;

7) more and better work in the field of exploitation of wildlife resources, such as those provided by game species or freshwater fish, that are subject to commercial exploitation or angling (Art. 7). These issues, prepared in collaboration with sport fishing and hunting organizations, would help to develop in practical terms the concepts of sustainable use of living resources;

8) an improved definition of the obligations on the control of the introduction of new genetic material in natural ecosystems (Art. 11, paragraph 2), including both nonnative species and Genetically Modified Organisms (GMOs);

9) effective action in the field of environmental education, dissemination of information, and promotion of public awareness of all aspects related to biodiversity conservation (as requested by Art. 3, paragraph 3 of the Bern Convention);

10) Promotion and coordination of research related to biodiversity conservation, as requested by Art. 11, paragraph $1 \mathrm{~b}$ of the Convention. This could take many forms, including the launching of specific research lines on priority subjects for conservation, or the creation of a Bern Convention label for research programmes with direct interest in the implementation of the Convention; and

11) strengthening of the cooperation aspects both with non-European parties (Burkina Faso, Senegal, and the other African countries invited to accede) and between Western and Eastern Europe. This could be done under the framework of Art. 1, paragraph 1 and Art. 11, paragraph la of the Convention.

The inclusion of new subjects and the re-enforcement of traditional ones in the work of the Bern Convention would strengthen its force, at the same time improving the regional implementation of many aspects of the Convention on Biological Diversity. Thus the Bern Convention has indeed a lot to offer to its parties, and it remains the main convention in the field of Nature and Biodiversity Conservation on the continental scale. The 'global' approach to conservation of biodiversity offered by the Convention would certainly help to give a more coherent European framework to intergovernmental activities in this field.

However, this Convention, or indeed any convention, will not succeed without the help and engagement of its parties. The Convention has been able to do in the last ten years an important amount of conservation work, mainly on European threatened wildlife, thanks to the financial support of the Council of Europe. It clearly needs now increased human and financial resources to carry out the above ambitious programme.

Eladio FERnANDEZ-Galiano Council of Europe F-67075 Strasbourg France.

\title{
Basic Features of the St Petersburg Region and Relevant Environmental Problems: Project for Solution
}

Tn various parts of the world, regional environmental proLlems are becoming more and more important (Gore, 1993; Kondratyev et al., 1993; Weizsäcker, 1994). The St Petersburg Region (SPR) is one of the most economically developed areas of Russia, being a huge interactive urban-rural complex involving a city having a population of 5 millions, with highly-developed industry and agriculture. The SPR is subject to a strong anthropogenic impact through the atmosphere and water systems (Fig. 1). The latter comprises the watershed of the Lake Ladoga-Neva River-Gulf of Finland system. This watershed is under the impact of the surrounding regions, and is a powerful source of pollution itself, especially for the Baltic Sea.

There is a high concentration of water-consuming industrial and agricultural units in the SPR, which are characteristic of a low (i.e. widely incomplete level of processing of raw materials into final products, in both the industrial and the agricultural sectors. This leads to the accumulation of large masses of waste, as well as to the pollution of water, soils, and the atmosphere, by toxic substances.

A specific feature of the SPR water system is the presence of various water-holding features - such as lakes, rivers, estuaries, the Gulf of Finland, and coastal zones which differ in the chemical composition of their waters, in the nature and scale of anthropogenic impacts, and further in their consequences. The acceleration of deforestation during recent years as a result of land privatization and the lack of its legal regulation, has led to the enhancement of soil erosion; it has also increased the runoff of phosphorus and nitrogen compounds, which has resulted in strong eutrophication of water-bodies. That is why the status of Lake Ladoga has become transformed from an oligotrophic to a mesotrophic (and sometimes eutrophic) state.

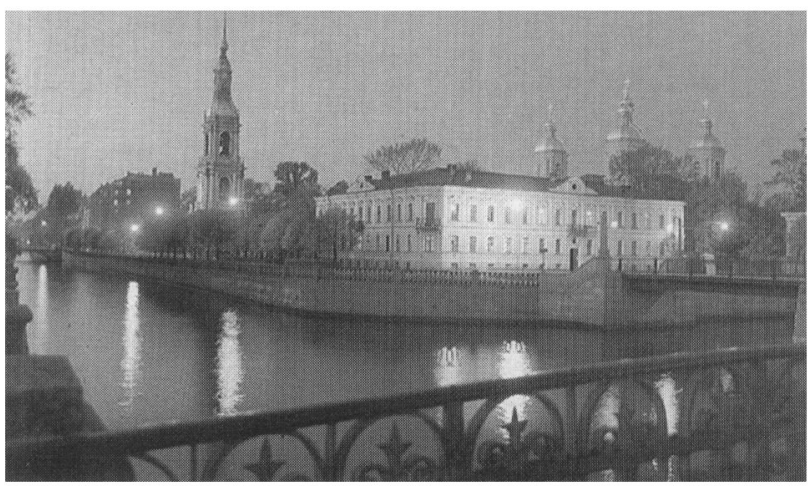

FIG. 1. Scene in St Petersburg, surely among the world's most magnificent waterside cities. 


\section{Early-warning System Needed}

An important problem to be solved is accomplishment and substantiation of an early-warning system for the entire SPR. From the viewpoint of the sustainable development of the region, the highest priority problems are the following:

1) accomplishment and substantiation of an optimal environmental monitoring system for the SPR, based on the application of both in situ and remote-sensing observation data;

2) numerical simulation modelling of land-use and water-resources exploitation under conditions of increasing anthropogenic loads;

3) studies of anthropogenically-influenced cycles of matter and energy for various natural systems and the whole SPR, as well as changes in the chemical composition of the environment under the impact of such processes as pollution, acidification, salinization, erosion, deforestation, and eutrophication;

4) assessments of stability limits for various ecosystems subject to anthropogenic impact; and

5) influence of environmental degradation on human health.

A special place belongs to problems of atmospheric and sea pollution. In the case of atmospheric pollution, the aim is to simulate changes in the chemical composition of the urban atmosphere with special emphasis on surface and tropospheric ozone dynamics - in view of its impact on human health, as well as on atmospheric aerosol transport and transformation (including transboundary transport) resulting from heterogeneous chemical reactions on particles. Aerosol dry- and wet-deposition processes deserve special attention in the context of toxic pollution of soils and waters. Drinking-water and contaminated agricultural production are practical aspects of the problem.

\section{Means of Solution?}

Towards solving the above-mentioned problems, the following means will be tested:

- techniques of regional-scale optimal planning-observing systems based on combined utilization of in situ and remote-sensing data;
- new approaches of remote sounding, with special emphasis on retrievals of atmospheric aerosol properties and hydrooptical parameters (concentration of phytoplankton, suspended matter, and dissolved organic matter), developed and verified on the basis of combined in situ and satellite (i.e. SeaWiFS*) observations; 3-D dynamic photochemical numerical models to simulate minor gas components' dynamics (a priority is surface ozone), as well as aerosol transformation and transport in the atmospheric boundary layer, verified by comparison with combined in situ and remote-sensing observations.

The eventual aim of the above Project is substantiation and accomplishment of an early-warning system concerning dangerous levels of pollutants in the atmosphere and natural waters (including assessments of transboundary transport). Such a system may be used for environmental management purposes.

\section{REFERENCES}

Gore, A. (1993). Earth in the Balance: Ecology and Human Spirit. PLUME, New York, NY, USA: 408 pp.

KondRatyeV, K.Y., Danilov-Danilyan, V.I., DonchenKo, V.K. \& Losev, K.S. (1993). Ecology and Politics. RAS, St Petersburg, Russia: 286 pp. (in Russian).

WeIsZÄcker, E.U. von (1994). Earth Politics. Zed Books Ltd, London and New Jersey: $243 \mathrm{pp}$.

KIRILL YAKOVLEVICH KONDRATYEV, Counsellor
Research Centre for Ecological Safety
18 Korpusnaya Street
197042 St Petersburg
Russia,
$\quad \&$
OLEG MIKHAILOVICH POKROVSKY, Laboratory Chief
Main Geophysical Observatory
7 Karbysheva Street
194018 St Petersburg
Russia.

* In answer to our query about this, Academician Kondratyev explained (in litt.) that is "is the title of an instrumentation set intended for measuring the sea colour.' - Ed.

\section{Conservation and Landscape of Historical Sites in India}

India is a country with a vast historical background. Through the ages, different rulers ruled different parts of the country for different periods, leaving their impact on the territories concerned in the form of:

(i) development of a region, e.g. construction of forts;

(ii) development of areas, e.g. palace complexes, temple complexes, market places; and

(iii) development of recreational areas, e.g. palace gardens, public gardens, play areas, squares, avenues, river banks, lakes, and reservoirs.

These things were built according to the respective culture, climatic conditions of the region, and functional requirement of the structure. As a result, we find a vast variety of historical sites spread all over the country, displaying a wide range of historical backgrounds. As time passes, the functional aspects of these areas/sites undergoes change, leading to neglect of the importance of the building and site, so that it becomes necessary to consider due preservation as well as conservaton of such places.
Conservation will chiefly be activated after realization that the natural and cultural resources of India are being eroded at an alarming rate. Some basic principles guiding the preservation and restoration of ancient buildings were defined for the first time in 1931, in a document known as the Athens Charter. Since 1903, India has been following the essential principles enshrined in earlier Charters, which were further modified and moulded into a Government Resolution in 1915 and published as a 'Conservation Manual'.

Against this background of current concepts, notions, and methods of conservation, we find that, while the methods of conservation followed in India are good and the outcome of following them is often of a commendable standard, the concept of conservation of a monument together with its surroundings, including the vegetation, has not gained any currency here. Thus the concept of conservation of an area and its landscape is quite new in India, where the governments' responsibility in conserving cul- 